\title{
Biochemical Markers of Environmental Stress Tolerance in Finger Millet [Eleusine coracana (L) Gaertn] Germplasm of Central Himalayan Region
}

Ajaya Kumar Trivedi ( $\square$ ajayakumartrivedi@gmail.com )

National Bureau of Plant Genetic Resources

S. K. Verma

ICAR-NBPGR, RS Bhowali

R. K. Tyagi

ICAR-NBPGR, Pusa, New Delhi

A. Hemanataranjan

Banaras Hindu University

\section{Research Article}

Keywords: Finger millet, Genetic diversity, Glutathione, Ascorbate, biomarkers.

Posted Date: August 11th, 2021

DOI: https://doi.org/10.21203/rs.3.rs-717780/v1

License: (c) This work is licensed under a Creative Commons Attribution 4.0 International License. Read Full License 


\section{Abstract}

Round the globe, availability of the germplasm of suitable crops for cultivation in remote, inaccessible and resource poor terrains is crucial for food security in these regions. Rich diversity of millets, which are highly tolerant to extreme weather conditions, is available in the Central Himalayan Region (CHR). However, biochemical evaluation of available germplasm for food security is a major issue yet to be addressed properly. In this backdrop plant exploration and germplasm collection expeditions were conducted to collect and evaluate the genetic diversity of finger millet (Fig. 1).

A total of 314 accessions having traits of agronomic importance were collected and evaluated for three consecutive years. In addition to battery of biochemical traits, yield was recorded to find out suitable germplasm for large scale cultivation/ breeding programme. At flowering stage variability in antioxidants level of leaves such as glutathione and ascorbate ranged from $105.27-423.63 \mathrm{mmol} . \mathrm{g}^{-1} \mathrm{FW}$ and $4.89-$ $10.21 \mathrm{mmol} . \mathrm{g}^{-1} \mathrm{FW}$ respectively. Extensive variability in the activity of enzymes important for multiple abiotic stress tolerance viz., catalase (115 - $855 \mathrm{mmol}$ hydrogen peroxide decomposed. $\mathrm{min}^{-1} \cdot \mathrm{mg}^{-1}$ protein), peroxidase (1.24 - $6.35 \mathrm{mmol}$ substrate. $\mathrm{min}^{-1} \cdot \mathrm{mg}^{-1}$ protein), superoxide dismutase (1236 - 2963 enzyme U.mg-1 protein), glutathione reductase ( $0.53-2.14 \mathrm{mmol}$ substrate. $\mathrm{min}^{-1} . \mathrm{mg}^{-1} \mathrm{protein}^{-1}$, ascorbate peroxidase (1.86 - $7.04 \mathrm{mmol}$ substrate. $\mathrm{min}^{-1} . \mathrm{mg}^{-1}$ protein), monodehydroascorbate reducatase $\left(1.11-4.41 \mathrm{mmol}\right.$ substrate. $\mathrm{min}^{-1} \cdot \mathrm{mg}^{-1}$ protein), dehydroascorbate reducatase $\left(0.34-1.36 \mathrm{mmol}\right.$ substrate. $\mathrm{min}^{-1} \cdot \mathrm{mg}^{-1}$ protein) was also recorded. Worldwide Abiotic/ environmental stresses hamper agricultural production. Enzymatic and non-enzymatic defence system precisely controls this situation. Hence, biochemical evaluation might be an appropriate strategy for identification of suitable germplam to combat the problem of food security in such areas.

\section{Introduction}

Globally, judicious use of fertilizers and plant protection chemicals, although significantly improved food grain availability; however in turn created a peril to sustainable food production system. Therefore, current focus of agricultural research is towards sustainability, organic production and climate compliant germplasm/ varieties to cater the current needs and be fitting for future obligations. Central Himalayan Region (CHR) is known for its biological richness as well as vulnerability to natural disasters. Unpredictable extreme weather, climate events and natural disasters prevalent in this region have the potential to upset the normal life processes of plants and damage agro-biodiversity. As compared to other regions, impact of climate change was found to be more in CHR such as warming in Himalayan Region is about 2-3 times higher than global average of $0.74^{\circ} \mathrm{C}$ during the last 100 years (Du et al.2004; IPCC 2007) which is adversely affecting plant processes. Although, plants monitor their surroundings continuously and adjust their metabolic systems accordingly to optimize productivity, however, in different genotypes degree of plasticity varies to a large extent. Therefore, for sustainable food production in such regions, identification, selection and availability of suitable plant genetic resources is a challenge.

Finger millet [Eleusine coracana (L) Gaertn] is a fast growing cereal crop that reaches maturity within 3 to 6 months (Dida and Devos 2006). It is commonly found at altitudes between 1000 to $2000 \mathrm{~m}$ asl in eastern and southern Africa and up to 2500 to $3000 \mathrm{~m}$ asl in the Himalayas (Dida and Devos 2006; FAO 2012). It is an important minor millet grown in more than 25 countries and accounts for $12 \%$ of the global millet area (ICRISAT 2008). It is usually grown in rainfed areas, problem soils, abiotic stress prone regions where other crops are not performing well. These areas are mostly in Africa and Asia where food and nutritional security is still a major problem. Finger millet has been recognized as a highly nutritious food for the weak and immuno-compromised people (Takan et al. 2012). In spite of comparatively stable yield in adverse environmental conditions, genetic diversity of finger millet has not yet been tapped for crop improvement in addition to remaining undescribed, being poorly understood and under-utilized (Upadhyaya 2008). Reason for yield stability in unfavourable environmental conditions is yet to be worked out to harness the untapped potential. In natural condition plants are exposed to wide array of environmental factors. Being sessile in nature plants are forced to sustain in stressful conditions. This in turn reduces production and productivity (Shao et al. 2008). Survival and successful reproduction under stressful environment is a complex phenomenon and decisive for sustainable agricultural production and food security. It is synchronized and regulated by array of physiological, cellular and molecular activities of plants (Ahuja et al. 2010). Plants survive in stressful environment at physiological cost (Massad et al. 2012). This becomes a major constraint for growth, development and leads yield reduction by more than $50 \%$ for major crops (Bray et al. 2000). However, available variability with respect to tolerance of environmental conditions might be harnessed. The consequence of exposure to unfavourable environmental stresses is oxidative damage via generation of reactive oxygen species (ROS) which disrupt cellular homeostasis thus affecting cell viability (Alscher et al. 1997; Bartels and Sunkar 2005).

Dynamics of cellular reduction/ oxidation (redox) processes, particularly the regulated accumulation of reactive oxygen species (ROS), play important roles in signalling appropriate responses to changes in the environmental conditions (Considine et al., 2015). Variation in regulation of this redox cycle in different accessions leads variation in the tolerance of germplasm. Apparently, invisible environmental stresses in the field condition cause oxidative stress and generation of reactive oxygen species (ROS) in plants. Particularly in CHR within plant species variability in generation and scavenging of ROS exists in the germplasm. ROS is scavenged by enzymes such as superoxide dismutases, 
catalases, ascorbate peroxidases, glutathione peroxidases as well as compounds including ascorbate and glutathione (Mittler 2002; Mittler et al. 2004; Mittler et al. 2011). However, relationship between the status of these enzymes/ antioxidants, performance of plants and yield stability has not been investigated properly particularly in minor millets such as finger millet. This may be utilized as biomarker for selection of desired genotypes to improve agricultural production stress in prone areas. Finger millet, suffers from limited funding for research, lack of agronomic recommendations and changing farming systems that increase likelihood of genetic erosion. Identification of biomarkers for stress tolerance as well as suitable varieties for different agro climatic conditions is yet lacking. Thus the outcome of the study may be useful for selection of suitable genotypes for conservation, crop improvement, large scale cultivation and improving production of finger millet as well as gene bank management.

\section{Materials And Methods Plant Material}

Exploration expeditions were conducted in the Central Himalayan Region of India to collect the untapped genetic diversity of finger millet [Eleusine coracana (L) Gaertn] (Fig. 2a, b, c). A total of 314 accessions having traits of agronomic importance were collected from altitudinal range of 225-2250 $\mathrm{m}$ amsl.

Collected germplasm was evaluated in the field in rain fed condition at an experimental site located at $29^{\circ} 24^{\prime} 28.7^{\prime \prime} \mathrm{N}$ latitude, $79^{\circ} 30^{\prime} 47.2^{\prime \prime} \mathrm{E}$ longitude and $1480 \mathrm{~m}$ asl altitude. Four checks (two improved varieties released for this region i.e., VL-146, VL-149 and two local accessions widely cultivated in the region i.e., Almora Local and Pithoragarh Local) were used for comparison to evaluate the collected germplasm. Experiments were conducted during June - October (Kharif season) for three consecutive years i.e., 2011-2013 in augmented block design $(A B D)$. Five representative plants of each accession were tagged in each block for recording the observations (Trivedi et al. 2015).

\section{Biochemical Analysis}

Catalase (EC 1.11.1.6) activity has been determined by consumption of hydrogen peroxide (Rao et al. 1996) and peroxidase (EC 1.11.1.7) activity by the method of Cordemener et al. (1991). Superoxide dismutase (SOD) (EC 1.15.1.1) activity, the basis of which is its ability to inhibit the photochemical reduction of nitroblue tetrazolium (Beauchamp and Fridovich 1971) has been assayed as per the procedure described by Stewart and Bewley (1980). The generation rate of superoxide radical $\left(\mathrm{O}_{2}^{-} \cdot\right)$ has been determined following the method of Wang and Luo (1990).

Glutathione content [reduced glutathione (GSH) and oxidized glutathione (GSSG)] has been determined enzymatically using the method of Griffith (1980). Determination of glutathione by this method is based on the specificity of glutathione reductase. Total glutathione and GSSG contents were determined directly and GSH after subtraction of GSSG from total glutathione. To determine GSSG, GSH of the sample was derivatized by adding $8 \mu \mathrm{L}$ of 2-vinylpyridine to $200 \mu \mathrm{L}$ of metaphosphoric extract that has been neutralized with $72 \mu \mathrm{L}$ of $1 \mathrm{M}$ triethanolamine. After vortexing for $30 \mathrm{~s}$, the mixture was allowed to incubate for $1 \mathrm{~h}$ at $25^{\circ} \mathrm{C}$. An aliquot of the extract $(40 \mu \mathrm{L}$ of metaphosphoric extract and $150 \mu \mathrm{L}$ of the 2-vinylpyridine derivatized extract) was added to the reaction medium for total glutathione and GSSG determination respectively which consists of phosphate buffer ( $50 \mathrm{mM}, \mathrm{pH} 7.5)$, EDTA (2.5 mM), DTNB (1 mM), GR (0.5 unit, baker yeast type III, Sigma), NADPH $(0.1 \mathrm{M})$ in a final volume of $1 \mathrm{~mL}$ at $25^{\circ} \mathrm{C}$. Reaction was started with the addition of the NADPH, the increase in absorbance at $412 \mathrm{~nm}$ was monitored for $3 \mathrm{~min}$ at $25^{\circ} \mathrm{C}$. Calibration curves were drawn using standards of GSH (1.6-80 IM) and GSSG (0.8$40 \mathrm{IM}$ ) prepared in 5\% (w/v) metaphosphoric acid. Glutathione reductase (GR) (EC 1.6.4.2) and glutathione S-transferase (GT) (EC 2.5.1.18) activity was measured by Smith et al. (1988) and Drotar et al. (1985) respectively.

Ascorbate content \{both reduced (AsA) and oxidized (DAsA)\} were determined as described by Knorzer et al. (1996), adapted from the bipyridyl method of Okamura (1980). In this method, AsA is determined directly and DAsA after reduction and subtraction of AsA from total ascorbate. For AsA determination, the metaphosphoric acid extract was neutralized with $25 \mu \mathrm{L}$ of $1.5 \mathrm{M}$ triethanolamine, vortexed and potassium phosphate buffer $(150 \mu \mathrm{L}, 0.15 \mathrm{M}, \mathrm{pH} 7.4)$ as well as $\mathrm{H}_{2} \mathrm{O}(150 \mu \mathrm{L})$ were added. Ten percent (w/v) trichloroacetic acid (300 $\left.\mu \mathrm{L}\right), 44 \%(\mathrm{v} / \mathrm{v})$ phosphoric acid $(300 \mu \mathrm{L}), 4 \%(\mathrm{w} / \mathrm{v})$ 2,2'- dipyridy $1\left(300 \mu \mathrm{L} 70 \%\right.$ ethanol) and $3 \%(\mathrm{w} / \mathrm{v}) \mathrm{FeCl}_{3}(150 \mu \mathrm{L})$ were added successively to the mixture. After vortexing, samples were incubated at $37^{\circ} \mathrm{C}$ for $60 \mathrm{~min}$ and absorbance was recorded at $525 \mathrm{~nm}$. For determination of total ascorbate, triethanolamine and potassium phosphate buffer were added to the metaphosphoric extract as described above and then $75 \mu \mathrm{L}$ dithiothretol (DTT) $10 \mathrm{mM}$ was added to the sample instead of water. The mixture was incubated for $15 \mathrm{~min}$ at $25^{\circ} \mathrm{C}$ to reduce DAsA to AsA. Excess DTT was removed by adding $75 \mu \mathrm{L}$ of $0.5 \%(\mathrm{w} / \mathrm{v}) \mathrm{N}$-ethylmaleimide. After mixing, the samples were incubated for 2 min at $25^{\circ} \mathrm{C}$ and determination of AsA proceeded as above. Standards of AsA and DAsA (50-600 $\mu \mathrm{M})$ prepared in $5 \%(\mathrm{w} / \mathrm{v})$ metaphosphoric acid were used for calibration. Monodehydro ascorbate reductase (MDHAR) (EC 1.6.5.4) and Dehydro ascorbate reductase (DHAR) (EC 1.8.5.1) activity was assayed

Page $3 / 16$ 
according to method given by Hossain et al. (1984) and Hossain and Asada (1984) respectively. Yield in terms of dry grain weight was recorded after harvesting.

\section{Statistical analysis}

The statistical analysis was performed using statistical software SAS 9.3.

\section{Results}

Activity of catalase, enzyme responsible for the degradation of hydrogen peroxide ranged from $115-855 \mu$ mol hydrogen peroxide

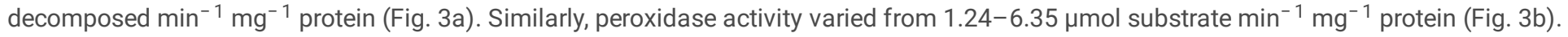
Superoxide dismutase activity, which catalyzes the dismutation of superoxide radicals (02-) to molecular oxygen (02) and hydrogen peroxide (H2O2), was found to vary 1236-2963 enzyme $\mathrm{U} \mathrm{mg}^{-1}$ protein (Fig. 3c). Likewise, superoxide free radical was also found to vary $0.63-4.29$ nmol hydrogen peroxide formed. $\mathrm{mg}^{-1}$ protein (Fig. 3d).

Total glutathione content in the collected gene pool were found to vary from 105.27 to 423.63 mmol.g ${ }^{-1} \mathrm{FW}$. In the best available genotype (best check) glutathione content were $296.41 \mathrm{mmol} . \mathrm{g}^{-1} \mathrm{FW}$ (Fig. 4a), which is only $69.96 \%$ of maximum value available in the collected germplasm. Plants maintain major part of antioxidant in the reduced form, however, drastic variability was found in reduced glutathione content among genotypes which varied 96.22 to $387.20 \mathrm{mmol} . \mathrm{g}^{-1} \mathrm{FW}$ (Fig. 4b), ensuing variability in oxidized glutathione content was also found i.e., oxidized glutathione content ranged 9.18 to 36.94 mmol.g ${ }^{-1} \mathrm{FW}$ (Fig. 4c). Variation in glutathione reductase (GR) activity was in

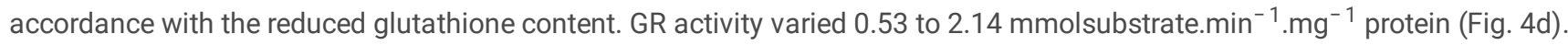

Similarly, variation in the total ascorbate content among genotypes was 4.89 to $10.21 \mathrm{mmol}^{-1} \mathrm{~g}^{-1} \mathrm{FW}$ (Fig. 5a), whereas ascorbic acid content varied 4.24 to $8.60 \mathrm{mmol} . \mathrm{g}^{-1} \mathrm{FW}$ (Fig. 5b). Dehydroascorbic acid (oxidized form of ascorbic acid) contents were found to vary 0.68 to 1.66 mmol.g $\mathrm{g}^{-1} \mathrm{FW}$ (Fig. 5c). In different accessions, noteworthy variability was found in the ascorbate peroxidase activity which ranged from 1.86 to $7.04 \mathrm{mmol}$ substrate. $\mathrm{min}^{-1} \cdot \mathrm{mg}^{-1}$ protein (Fig. $5 \mathrm{~d}$ ). Activity of monodehydroascorbate reductase, an enzymatic component of the glutathione-ascorbate cycle was found to vary 1.11 to $4.41 \mathrm{mmolsubstrate} \cdot \mathrm{min}^{-1} \cdot \mathrm{mg}^{-1}$ protein (Fig. 5e). Similarly, dehydroascorbate reductase activity varied 0.34 to 1.36 mmolsubstrate. $\mathrm{min}^{-1} . \mathrm{mg}^{-1}$ protein (Fig. $5 \mathrm{f}$ ).

Ample variation in the yield of collected germplasm was found which ranged 4.39 to 12.82 g.plant $^{-1}$ (Fig. 6). Plants need optimal temperature and moisture during sowing, germination and at seedling establishment stage. However, irregular temperature and precipitation pattern at the experimental site (Table 1) exposes plants to multiple environmental stresses including radical variation in the soil moisture level in this mountainous terrain. In the year 2011 there was 459 mm rain fall during the month of June while in the year 2012 it was only 84.4 mm, again during the year 2013 there was $524.5 \mathrm{~mm}$ rainfall. Plants face similar fluctuations in environmental variables during the whole life span.

Temperature variation influences most of the plant activities including seed germination, plant growth and development, crop maturation and yield. Considerable variation in the mean monthly minimum and maximum temperature was recorded during the life span of crop; amplitude of diurnal variation was quite large.

Table 1

Mean monthly precipitation and temperature variation at experimental site during the experiment

\begin{tabular}{|c|c|c|c|c|c|c|c|c|c|}
\hline \multirow[t]{3}{*}{ Month } & \multicolumn{3}{|c|}{ Precipitation (mm) } & \multicolumn{6}{|c|}{ Temperature $\left({ }^{\circ} \mathrm{C}\right)$} \\
\hline & \multirow[t]{2}{*}{2011} & \multirow[t]{2}{*}{2012} & \multirow[t]{2}{*}{2013} & \multicolumn{2}{|l|}{2011} & \multicolumn{2}{|l|}{2012} & \multicolumn{2}{|l|}{2013} \\
\hline & & & & Min & Max & Min & Max & Min & Max \\
\hline June & 459 & 84.4 & 524.5 & 15.88 & 25.84 & 16.8 & 25.48 & 17.71 & 25.42 \\
\hline July & 251.4 & 585 & 183.7 & 18.56 & 25 & 14.96 & 25.72 & 18.88 & 23.73 \\
\hline August & 515 & 236 & 259 & 18.17 & 24.78 & 16.65 & 25.13 & 15.17 & 25.08 \\
\hline September & 146 & 341 & 47 & 14.92 & 26 & 16.16 & 25.12 & 18.91 & 26.16 \\
\hline October & 0 & 0 & 7 & 11 & 26.65 & 12.56 & 25.82 & 11.62 & 22.29 \\
\hline
\end{tabular}


Clustering partitions data sets into groups such that the similarity within a group is larger than among the groups. Cluster analysis was done by Ward's method (Cophen. Corr.: 0.8406) to divide the observations into homogeneous and distinct groups, two main clusters were formed. These clusters were further divided into five sub clusters. Hence, k-means clustering was done to divide all the 318 accessions into five clusters (Table 2). Accessions with similar traits were found to group together. One hundred twenty four accessions grouped in cluster one have very close similarity in the traits used in biochemical evaluation, this cluster includes two check accessions also, which are widely cultivated in the region. Amazingly, two local accessions widely cultivated in the region have similar traits, used as check (Almora Local and Pithoragarh Local) group together in cluster 1 and two improved varieties released for cultivation in the region (VL-146, VL-149), used as check group together in cluster 3 . Cluster 5 has minimum number of accessions i.e., 31; these all accessions show close similarity in the enzymes activity as well as antioxidant levels. Accessions present in a cluster may be useful for selection of similar genotypes for a particular trait as well as for breeding. 
Table 2

K-Mean clustering of the germplasm.

\begin{tabular}{|c|c|c|c|c|c|c|c|c|c|c|}
\hline S.No. & Cluster 1 & & & & Cluster 2 & Cluster 3 & & Cluster 4 & & Cluster 5 \\
\hline 1. & IC261946 & IC281432 & IC337282 & IC361318 & IC266775 & IC260911 & IC356405 & IC260925 & IC391548 & IC262000 \\
\hline 2. & IC261948 & IC281435 & IC337298 & IC361332 & IC273556 & IC260916 & IC382697 & IC261982 & IC391557 & IC266857 \\
\hline 3. & IC261950 & IC281450 & IC337299 & IC381467 & IC279406 & IC261960 & IC383401 & IC261996 & IC392497 & IC273933 \\
\hline 4. & IC261962 & IC281462 & IC337302 & IC383631 & IC279422 & IC261987 & IC383424 & IC262004 & IC392499 & IC279395 \\
\hline 5. & IC261968 & IC281465 & IC337311 & IC338576 & IC279469 & IC261991 & IC383577 & IC273932 & IC392520 & IC281442 \\
\hline 6. & IC261969 & IC281473 & IC337315 & IC391402 & IC279503 & IC261994 & IC383629 & IC279376 & IC393042 & IC281479 \\
\hline 7. & IC261972 & IC281476 & IC337320 & IC391409 & IC281437 & IC273964 & IC391332 & IC279566 & IC393050 & IC282784 \\
\hline 8. & IC261979 & IC281482 & IC337321 & IC391462 & IC281439 & IC273973 & IC391360 & IC279793 & IC393058 & IC337306 \\
\hline 9. & IC261998 & IC281485 & IC337326 & IC392484 & IC281460 & IC273977 & IC391434 & IC281446 & IC393059 & IC338632 \\
\hline 10. & IC266735 & IC281754 & IC337331 & IC392516 & IC281477 & IC273986 & IC391526 & IC281447 & IC418375 & IC355771 \\
\hline 11. & IC266759 & IC281756 & IC338637 & IC392548 & IC281488 & IC279352 & IC392493 & IC281453 & & IC355802 \\
\hline 12. & IC266909 & IC281758 & IC338644 & IC392564 & IC281743 & IC279487 & IC392505 & IC281466 & & IC356039 \\
\hline 13. & IC266941 & IC281763 & IC338646 & IC393023 & IC282787 & IC279517 & IC392605 & IC281489 & & IC356408 \\
\hline 14. & IC273998 & IC281766 & IC338649 & IC393029 & IC282792 & IC279534 & IC392616 & IC281745 & & IC361260 \\
\hline 15. & IC274001 & IC281768 & IC341035 & IC393030 & IC282795 & IC279624 & IC393018 & IC281751 & & IC382639 \\
\hline 16. & IC274172 & IC281770 & IC341363 & IC393034 & IC316036 & IC279725 & IC393019 & IC281752 & & IC391322 \\
\hline 17. & IC275038 & IC282790 & IC355774 & IC393044 & IC317429 & IC281417 & IC393020 & IC281761 & & IC391334 \\
\hline 18. & IC279342 & IC282797 & IC355809 & IC393046 & IC337226 & IC281444 & IC393025 & IC282782 & & IC392492 \\
\hline 19. & IC279414 & IC316025 & IC355813 & IC393049 & IC337252 & IC281448 & IC393037 & IC282796 & & IC392596 \\
\hline 20. & IC279585 & IC316027 & IC355814 & IC393061 & IC337308 & IC281747 & IC393039 & IC316029 & & IC393024 \\
\hline 21. & IC279610 & IC316030 & IC355815 & IC436959 & IC337323 & IC281772 & IC393048 & IC316041 & & IC393026 \\
\hline 22. & IC279830 & IC316035 & IC355816 & IC436973 & IC337325 & IC282779 & IC393052 & IC316044 & & IC393028 \\
\hline 23. & IC279843 & IC316037 & IC355817 & IC444160 & IC337337 & IC316028 & IC393057 & IC316049 & & IC393036 \\
\hline 24. & IC281415 & IC316040 & IC355818 & IC444225 & IC338562 & IC316039 & IC393060 & IC337309 & & IC393055 \\
\hline 25. & IC281419 & IC316048 & IC355819 & IC469853 & IC338643 & IC316043 & IC418383 & IC337322 & & IC444140 \\
\hline 26. & IC281422 & IC317454 & IC355821 & IC469877 & IC345586 & IC337227 & IC444158 & IC338645 & & IC469751 \\
\hline 27. & IC281423 & IC317458 & IC356000 & IC538018 & IC345599 & IC337269 & IC469755 & IC338647 & & IC469883 \\
\hline 28. & IC281424 & IC337231 & IC356400 & IC538079 & IC356413 & IC337310 & IC469795 & IC340980 & & IC469890 \\
\hline 29. & IC281426 & IC337237 & IC356402 & IC538090 & IC361360 & IC338636 & IC469814 & IC340990 & & IC538019 \\
\hline 30. & IC281429 & IC337244 & IC356411 & $\begin{array}{l}\text { Almora } \\
\text { Local }\end{array}$ & IC391423 & IC355783 & IC469826 & IC355782 & & IC538041 \\
\hline 31. & IC281431 & IC337248 & IC356412 & $\begin{array}{l}\text { Pithoragarh } \\
\text { Local }\end{array}$ & IC392487 & IC355787 & IC469886 & IC355785 & & IC538059 \\
\hline 32. & & & & & IC392526 & IC355788 & IC469901 & IC355790 & & \\
\hline 33. & & & & & IC393027 & IC355798 & IC538028 & IC355808 & & \\
\hline 34. & & & & & IC393032 & IC355812 & IC556540 & IC355810 & & \\
\hline 35. & & & & & IC393047 & IC356087 & VL-146 & IC355811 & & \\
\hline 36. & & & & & IC393053 & IC356394 & VL-149 & IC355820 & & \\
\hline
\end{tabular}




\begin{tabular}{|c|c|c|c|c|}
\hline S.No. Cluster 1 & Cluster 2 & Cluster 3 & Cluster 4 & Cluster 5 \\
\hline 37. & IC418381 & IC356397 & IC356409 & \\
\hline 38. & IC538058 & IC356398 & IC391391 & \\
\hline 39. & IC556537 & IC356399 & IC391511 & \\
\hline
\end{tabular}

It is evident from principal component analysis and percentage contribution of each component to the total variation (Table 3 ) that first four variables contributed 99.99802 percent of the total variability. First component accounted for $86.218 \%$, second principal component contributed $9.7035 \%$, third principal component $4.0733 \%$ and fourth principal component contributed $0.00322 \%$ of the total variability. It is evident from scree plot of the principal components (Fig. 7) that only four principal components are considerably contributing towards diversity.

Table 3

Contribution of the first four principal component axes to variation in finger millet [Eleusine coracana (L) Gaertn] based on biochemical traits

\begin{tabular}{|c|c|c|c|c|c|}
\hline S. & Parameter & PC 1 & PC 2 & PC 3 & PC 4 \\
\hline 1. & Catalase activity (mmol hydrogen peroxide decomposed.min-1.mg -1protein) & 0.091528 & 0.99566 & -0.01635 & -0.00219 \\
\hline 2. & Peroxidase activity (m mol substrate.min-1. mg-1 protein) & 0.000218 & -0.00134 & 0.002594 & -0.05182 \\
\hline 3. & Superoxide dismutase activity (enzyme U.mg -1protein) & 0.99579 & -0.09143 & 0.006329 & 0.000808 \\
\hline 4. & $\begin{array}{l}\text { Super oxide free radical (02.-) formation (nmol hydrogen peroxide } \\
\text { formed.mg-1 protein) }\end{array}$ & -0.00043 & -0.0014 & 0.001497 & 0.006939 \\
\hline 5. & Total Glutathione (mmol.g-1 FW) & -0.00371 & 0.012934 & 0.73645 & 0.30714 \\
\hline 6. & Reduced Glutathione (mmol.g-1 FW) & -0.00302 & 0.010679 & 0.67323 & -0.40352 \\
\hline 7. & Oxidized Glutathione (mmol.g-1 FW) & -0.00075 & 0.002389 & 0.063256 & 0.71181 \\
\hline 8. & Glutatione Reductase (mmol substrate.min-1. mg-1 protein) & $-1.72 \mathrm{E}-05$ & $5.70 \mathrm{E}-05$ & 0.003717 & -0.00229 \\
\hline 9. & Total Ascorbate (mmol.g-1 FW) & 0.000624 & -0.00188 & 0.000213 & -0.0637 \\
\hline 10. & Reduced Content (mmol.g-1 FW) & 0.000566 & -0.00179 & 0.00035 & -0.08039 \\
\hline 11. & Dehydroascorbic Acid (mmol.g-1 FW) & 2.11E-05 & -0.00031 & 0.000297 & 0.00224 \\
\hline 12. & Ascorbate Peroxidase (mmolsubstrate.min-1.mg-1 protein) & 0.000697 & 0.00031 & 0.006458 & 0.1471 \\
\hline 13. & Monodehydroascorbate Reductase (m mol substrate.min-1. mg-1 protein) & 0.00039 & 0.000134 & 0.004039 & 0.090881 \\
\hline 14. & Dehydroascorbate Reductase (m mol substrate.min-1. mg-1 protein) & 0.000131 & 2.84E-05 & 0.001254 & 0.029074 \\
\hline 15. & Yield. Plant-1 (g) & 0.000433 & -0.00117 & 0.00178 & -0.43835 \\
\hline 16. & Eigen values of the covariance matrix & 263070 & 29607.6 & 12428.7 & 9.82739 \\
\hline 17. & Contribution (percent) & 86.218 & 9.7035 & 4.0733 & 0.0032208 \\
\hline 18. & Cumulative contribution (percent) & 86.218 & 95.9215 & 99.9948 & 99.99802 \\
\hline
\end{tabular}

\section{Discussion}

The CHR of India is facing a great challenge to produce more and more from diminishing per capita arable land where intensity and frequency of abiotic/ environmental stresses is comparatively more than other regions. Climate change, deforestation and increasing anthropogenic activities are affecting sustainable traditional agricultural system of the region. Plant growth, development and production of economic yield depend largely on the environmental conditions during different phases of growth and development. However, under natural condition in the field, plants face multiple environmental stresses. In the fluctuating environmental conditions in the field germplasm able to sustain and produce economic yield might have specific biochemical regulation. In most of the cases experiments designed for stress tolerance are conducted in the laboratory and consider plant responses to individual stress (Todaka et al. 2012; Qin et al. 2011). However, the response to multiple stresses is much more complex (Fujita et al. 2006). Hence, in the present investigation, experiments were conducted in the field to assess and compare the relative performance of whole finger millet germplasm of CHR of India and screen out suitable accessions. 
As a consequence of exposure to environmental stress, reactive oxygen species (ROS) are generated quickly (Laloi et al. 2004; Foyer and Noctor 2005). This leads to reprogramming of the genetic machinery, in turn causes an increase in tolerance to abiotic/ environmental stress. Over expression of the gene for catalase enzyme activity protects leaves against ROS (Zelitch et al. 1991), while catalase deficient plants are more sensitive to various stresses (Willekens et al. 1997). More than seven fold variability was found in the catalase activity of different accessions which will lead to considerable variation in the environmental stress tolerance of the germplasm. Catalase lowers oxidative damage by converting hydrogen peroxide to water and oxygen (Scandalios et al. 1993). On the other hand, scavenging of super oxide by SOD is an important mechanism to cope with stress condition (Bowler et al. 1992). Small quantity of superoxide free radical was also found which may be scavenged simultaneously by SOD. Significant variability in peroxidase activity was recorded which is related to the generation and use of ROS (Van Huystee 1987). Plant peroxidases exist in variety of isoforms that use different reductants and are located in different cellular compartments (Campa 1991). The variability in the activity of peroxidases in different accessions may be hypothesized as either due to difference in induction by substrate that may be $\mathrm{H}_{2} \mathrm{O}_{2}$ or due to difference in total protein. In plants, peroxidases are involved in numerous cellular processes such as development and stress responses. These enzymes are considered as biomarkers of environmental stress. Under stress conditions, the quantitative and qualitative profiles of peroxidases are generally modified. Such modifications are evidence of pivotal role played by these enzymes in the defence mechanism (Jouili et al. 2011).

In addition to variability in the activity of antioxidant enzymes, drastic variability in the redox state of antioxidant pool size was also found. Difference in the total glutathione content of various genotypes indicates variability in the capacity of these accessions to overcome environmental stress. Glutathione (GSH), an antioxidant, exerts number of functions in plants (Paranhos et al. 1999). Protection of cells against the toxic effects of the free radicals, to keep free-radical scavenging ascorbate in its reduced, hence, active form by involvement in the ascorbate-glutathione cycle are major functions (Zhang and Kirkham 1996). Although, significance of GSH as a reductant in ascorbate regeneration is established in relation to stress tolerance ((Aono et al. 1995; Mano et al. 1997) however, chemotyping of finger millet is yet lacking to screen the large population of germplasm. In addition, drastic variability in the glutathione reductase (EC 1.6.4.2) activity was also found which sustains the reduced status of GSH via ascorbate-glutathione pathway. Accessions found to be comparatively tolerant to environmental stress conditions have higher glutathione reductase activity that might be more availability of its substrate i.e., GSSG during stress condition as well as higher demand of its product GSH to sustain. Product GSH is important for a broad range of cellular functions, such as cell division (Rebhun et al. 1976), amino acid transport through membranes (Meister 1981), regulation of enzymatic activity (Holmgren 1979) etc. Environmental stress tolerance in genotypes having more GSH might be due to regulation of related enzymes at different levels.

Similarly, significant considerable variability in the ascorbate and ascorbate recycling enzymes \{i.e., monodehydroascorbate (MDA) reductase and dehydroascorbate (DHA) reductase\} activity was also found which increases in stress condition (Knorzer et al. 1996) and helps to stress tolerance. Recycling through these enzymes is essential for survival of plants. Without recycling of ascorbate, $\mathrm{H}_{2} \mathrm{O}_{2}$ would deplete the available ascorbate pool via ascorbate peroxidase within minutes (Hossain et al. 1984). Substantial variability in the activity of ascorbate peroxidase (APX) enzyme that detoxify peroxides using ascorbate as a substrate was recorded. APX is a key enzyme in the ascorbateglutathione cycle, the main hydrogen peroxide detoxification system in plants (Asada 1992). APX and ascorbate-glutathione cycle is pivotal in ROS scavenging in chloroplast, cytosol, mitochondria and peroxisomes (Mittler et al. 2004; Shigeoka et al. 2002). Glutathione-dependent DHA reductase activity recycles DHA to ascorbate (Hossain and Asada 1984). DHA is a essential component of ascorbate turnover as well as the ascorbate redox system (Foyer and Mullineaux 1998). An increase of DHA reductase activity and an accumulation of DHA are biochemical indicators of oxidative stress in plant metabolism (Wise 1995). Considerable increase in the DHA and corresponding increase in the DHA activity itself explicate the stress condition prevailing in the $\mathrm{CHR}$ and urgent need to screen the available germplasm to promote for large scale cultivation to ascertain the food security in this as well as other such areas.

In accordance with the present findings changes in oxidative stress related enzymes and redox state of antioxidant pool was found to be related with stress tolerance in proso millet [Panicum miliaceum] (Trivedi et al. 2015) and barnyard millet (Echinochloa frumentacea) (Trivedi et al. 2017) also. Enormous variability has been recorded in antioxidants and activity of oxidative stress enzymes which indicates potential of genotypes to cope with the stress condition. Stress compliant genotypes have been found to have more reduced glutathione as well as ascorbate. Reduced form of antioxidants in different accessions seems to be a suitable biomarker for chemotyping and germplasm screening particularly in this crop. On the basis of clustering of whole germplasm into five clusters having similar traits, appropriate germplasm may be selected for cultivation in areas prone to environmental/ abiotic stresses, cultivation in different agro climatic zones. Rapid perception of abiotic stresses by plants and appropriate estimation of biochemical adjustments in response to stress are critical to ensure future food security. Biochemical evaluation might be suitable approach for selection of suitable accessions for developing climate resilient varieties.

Since the CHR has witnessed several climate cycles in the geological past, the available germplasm should have experienced several changes, hence it is important to evaluate the whole germplasm and find out superior available to deal with present/ future challenges. 


\section{Conclusion}

Plants adjust redox status of antioxidants as an adaptation to stress and activity of related enzymes shifts accordingly. Measurement of redox status of antioxidants rather than total antioxidant pool might be a suitable approach to find out genotypes for cultivation in stress prone regions. In addition corresponding variability in the activity of stress related enzymes found to be a distinguishing indicator of stress tolerance. Genotypes having more reduced antioxidants (glutathione and ascorbate) have consistently better performance and have comparatively stable yield. Redox state of antioxidants might be an appropriate biomarker for chemotyping and utilization of the untapped genetic diversity of finger millet for improving agricultural production and food security. In different regions agricultural systems are challenged by climate change and abiotic/ environmental stresses. Hence, sustainable and judicious utilization of untapped genetic diversity might help farmers to adapt the change and sustain their livelihoods.

\section{Declarations}

\section{Acknowledgement}

Authors are thankful to Director, ICAR - National Bureau of Plant Genetic Resources, Pusa Campus, New Delhi for providing necessary facility and keen interest in the study. This manuscript is dedicated to Prof. A. Hemantaranjan, who left for heavenly abode on May 31, 2021 at the age of 66 , after a courageous battle with post-covid severe lung infection.

Author Declaration: Authors declare that there is no conflict of interest among authors.

\section{References}

Ahuja I., de vos RC, Bones AM, Hall RD (2010) Plant molecular stress responses face climate change. Trends Plant Sci 15: $1360-1385$

Alscher RG, Donahue JL, Cramer CL (1997) Reactive oxygen species and antioxidants: relationships in green cells. Plant Physiol 100: 224-233

Aono M, Saji H, Sakamoto A, Tanaka K, Kondo N, Tanaka K (1995) Paraquat tolerance of transgenic nicotiana tabacum with enhanced activities of glutathione reductase and superoxide dismutase. Plant Cell Physiol 36: 1687-1691

Asada K (1992) Ascorbate peroxidase - A hydrogen peroxide-scavenging enzyme in plants. Physiol Plant 85: $235-241$

Bartels D, Sunkar R (2005) Drought and salt tolerance in plants. Crit Rev Plant Sci 24: 23 - 58

Beauchamp C, Fridovich I (1971). Superoxide dismutase: Improved assay and an assay applicable to acrylamide. Anal Biochem 44: 276-287

Bowler C, Van Montagu M, Inze D (1992) Superoxide dismutase and stress tolerance. Ann Rev Plant Physiol Plant Mol Biol 43: $83-116$

Bray EA, Bailey-Serres J, Weretilnyk E (2000) Responses to abiotic stresses. In: Gruissem W., Buchannan, B. B., Jones, R. L. (Eds.) Biochemistry and Molecular Biology of Plants. Rockville: American Society of Plant Physiologists. p. 1158-1203.

Campa, A. (1991) Biological role of plant peroxidases: Known and potential functions. In: Everse, J., Everse, K. E., and Grisham, M. B. (Eds), Peroxidases in Chemistry and Biology. CRC Press. Inc. FL, pp 25-50

Considine1, M. J., Sandalio, L. M. and Foyer, C. H. (2015) Unravelling how plants benefit from ROS and NO reactions, while resisting oxidative stress. Annal. Bot. 116: 469-473

Cordemener J, Booij H, Van Zandt H, Van Engelen F, Van Kammen A, De Vries S (1991) Tunicamycin-inhibited carrot somatic embryogenesis can be restored by secreted cationic peroxidase isozymes. Planta 184: 478-486

Dida MM, Devos KM (2006) Finger millet. In: Chittarajan, K., Genome Mapping and Molecular Breeding in Plants, Springer-Verlag, 1: $333-344$

Du, M. Y., Kawashima, S., Yonemura, S., Zhang, X. Z. and Chen, S. B., 2004. 'Mutual influence between human activities and climate change in the Tibetan Plateau during recent years.' Global and Planetary Change, 41(3-4): 241-249.

FAO (2012) Grassland Index. A searchable catalogue of grass and forage legumes. FAO, Rome, Italy

Foyer C, Noctor G (2005) Redox homeostasis and antioxidant signaling: A metabolic interface between stress perception and physiological responses. Plant Cell 17: 1866-1875 
Foyer CH, Mullineaux PM (1998) The presence of dehydroascorbate and dehydroascorbate reductase in plant tissues. FEBS Lett 425: 528-529

Fujita M, Fijita Y, Noutoshi Y, Takahashi F, Narusaka Y, Yamaguchi-Shinozaki K, Shinozaki K (2006) Crosstalk between abiotic and biotic stress responses: A current view from the points of convergence in the stress signaling networks. Curr Opin Plant Biol 9: 436-442

Griffith OW (1980) Determination of glutathione and glutathione disulfide using glutathione reductase and 2-vinylpyridine. Anal Bioch 106: 207-212

Holmgren A (1979) Glutathione-dependent synthesis of deoxiribonucleotides. Characterization of the enzymatic mechanism of Escherichia coliglutaredoxin. J Biol Chem 254: 3672-3678

Hossain MA, Asada K (1984) Purification of dehydroascorbate reductase from spinach and its characterization as a thiol enzyme. Plant Cell Physiol 25: 85-92

Hossain MA, Nakano Y, Asada K (1984) Monodehydroascorbate in spinach chloroplasts and its participation in regeneration of ascorbate for scavenging hydrogen peroxide. Plant Cell Physiol 25: 385-395

I. P. C. C., 2007. Intergovernmental Panel on Climate Change fourth assessment report: Climate change. Synthesis Report. World Meteorological Organization, Geneva, Switzerland.

ICRISAT (2008) ICRISAT/Gene bank activities; www.icrisat.org/genebank

Jouili H, Bouazizi H, Ferjani EE (2011) Plant peroxidases: biomarkers of metallic stress. Acta Physiol Plant 33 (6): $2075-2082$

Knorzer OC, Durner J, Boger P (1996) Alterations in the antioxidative system of suspension-cultured soybean cells (Glycine max) induced by oxidative stress. Physiol Plant 97: 388-396

Laloi C, Appel K, Danon A (2004) Reactive oxygen signaling: The latest news. Curr Opin Plant Biol 7: $323-328$

Mano J, Ushimarn T, Asada K (1997) Ascorbate in thylakoid lumen as an endogenous electron donor to Photosystem II: Protection of thylakoids from photoinhibition and regeneration of ascorbate in stroma by dehydroascorbate reductase. Photosynth Res 53: $197-204$

Massad TJ, Dyer LA, Vega CG (2012) Cost of defense and a test of the carbon-nutrient balance and growth-differentation balance hypotheses for two co-occurring classes of plant defence. PLoS One 7: e7554

Meister A (1981) Metabolism and functions of glutathione. Trends Biochem Sci 6: 231-234

Mittler R (2002) Oxidative stress, antioxidants and stress tolerance. Trends Plant Sci 7: 405-410

Mittler R, Vanderauwera S, Gollery M, Breusegem FV (2004) Reactive oxygen gene network of plants. Trends Plant Sci 9: 490-498

Mittler R, Vanderauwera S, Suzuki N, Miller G, Tognetti VB, Vandepoele K, Gollery M, Shulaev V, Breusegem FV (2011) ROS signaling: the new wave? Trends Plant Sci 16: 300-309

Okamura, M (1980) An improved method for determination of L-ascorbic acid and L-dehydroascorbic acid in blood plasma. Clin Chim Acta 103: $259-268$

Paranhos A, Fernandez-Tarrago J, Corchete P (1999) Relationship between active oxygen species and cardenolide production in cell cultures of Digitalis thapsi: Effect of calcium restriction. New Phytol 141: 51-60

Qin F, Shinozaki K, Yamaguchi-Shinozaki K (2011) Achievements and challenges in understanding plant abiotic stress responses and tolerance. Plant Cell Physiol 52: 1569-1582

Rao MV, Paliyath G, Ormrod DP (1996) Ultraviolet B and Ozone induced biochemical changes in antioxidant enzymes of Arabidopsis thaliyana. Plant Physiol 110: 125-136

Rebhun LI, Miller M, Schnaitman TC, Nath J, Mellon M (1976) Cyclic nucleotides, thioldisulfide status of proteins, and cellular control processes. J Supramol Struct 5: 199-219

Scandalios JG (1993) Oxygen stress and superoxide dismutase. Plant Physiol 101: 7-12

Page 10/16 
Shalata A, Tal M, (1998) The effect of salt stress on lipid peroxidation and antioxidants in the leaf of the cultivated tomato and its wild salt tolerant relative Lycopersicon pennelli. Physiol Plant 104: 169-174

Shao HB, Chu LY, Jaleel CA, Zhao CX (2008) Water-deficit stress-Induced anatomical changes in higher plants. Comptes Rendus Biol 331: 215225

Shigeoka S, Ishikawa T, Tamoi M, Miyagawa Y, Taked T, Yabuta Y, Yoshimura K (2002) Regulation and function of ascorbate peroxidase isoenzymes. J Exp Bot 53: 1305-1319

Smith IK, Vierhelle TL, Thorne CA (1988) Assay of glutathione reductase in crude tissue homogenates using 5,5'-dithiobis (2-nitrobenzoic acid). Anal Biochem 175: 408-413

Stewart RRC, Bewley JD (1980) Lipid Peroxidation associated with accelerated aging of soybean axes. Plant Physiol 65: 245-248

Takan JP, Chipili J, Muthumeenakshi S, Talbot, NJ, Manyasa, EO, Bandyopadhyay R, Sere Y, Nutsugah SK, Talhinhas P, Hossain M, Brown AE, Prasad SS (2012) Magnaporthe oryzae Populations Adapted to Finger Millet and Rice Exhibit Distinctive Patterns of Genetic Diversity, Sexuality and Host Interaction. Mol Biotech 50: 145-158

Todaka D, Nakashima K, Shinozaki K, Yamaguchi-Shinozaki K (2012) Toward understanding transcriptional regulatory networks in abiotic stress responses and tolerance in rice. Rice J 5: 1-9

Trivedi AK, Arya L, Verma M, Verma SK, Tyagi RK, Hemantaranjan A (2015) Genetic Variability in proso millet [Panicum miliaceum] germplasm of Central Himalayan Region based on morpho-physiological traits and molecular markers. Acta Physiol Plant 37: 23 (DOI 10.1007/s11738014-1770-y)

Trivedi, AK, Arya L, Verma SK, Tyagi RK, Hemantaranjan A (2017) Evaluation of barnyard millet diversity in central Himalayan region for environmental stress tolerance. J Agric Sci 1 - 11 doi;10.1017/S0021859617000545

Upadhyaya HD, Pundir RPS, Gowda CLL, Reddy VG, Singh S (2008) Establishing a core collection of foxtail millet to enhance utilization of germplasm of an underutilized crop. Plant Genet Resour 7: 177-184

Van Huystee RE (1987) Some molecular aspects of plant peroxidase biosynthetic studies. Ann Rev Plant Physiol 38, 205-219

Wang AG, Luo GH (1990) Quantitative relation between the reaction of hydroxylamine and superoxide anion radicals in plants. Plant Physiol Comm 6: 55-57

Willekens $\mathrm{H}$, Chamnongpol S, Davey M, Schraudner M, Langebartels C, Van Montagu M (1997) Catalase in sink for $\mathrm{H}_{2} \mathrm{O}_{2}$ and is indispensable for stress defense in $\mathrm{C}_{3}$ plants. EMBO 16: 4806-4816

Wise RR (1995) Chilling-enhanced photooxidation: The production, action and study of reactive oxygen species produced during chilling in the light. Photosynth Res 45: 79-97

Zelitch I, Havir EA, Mc Gonigle B, Mc Hale NA, Nelson T (1991) Leaf catalase mRNA and catalase-protein levels in a high-catalase tobacco mutant with $\mathrm{O}_{2}$ resistant photosynthesis. Plant Physiol 97: 1592-1595

Zhang J, Kirkham MB (1996) Lipid peroxidation in sorghum and sunflower seedlings as affected by ascorbic acid and propyl gallate. J Plant Physiol 149: 489-493

\section{Figures}




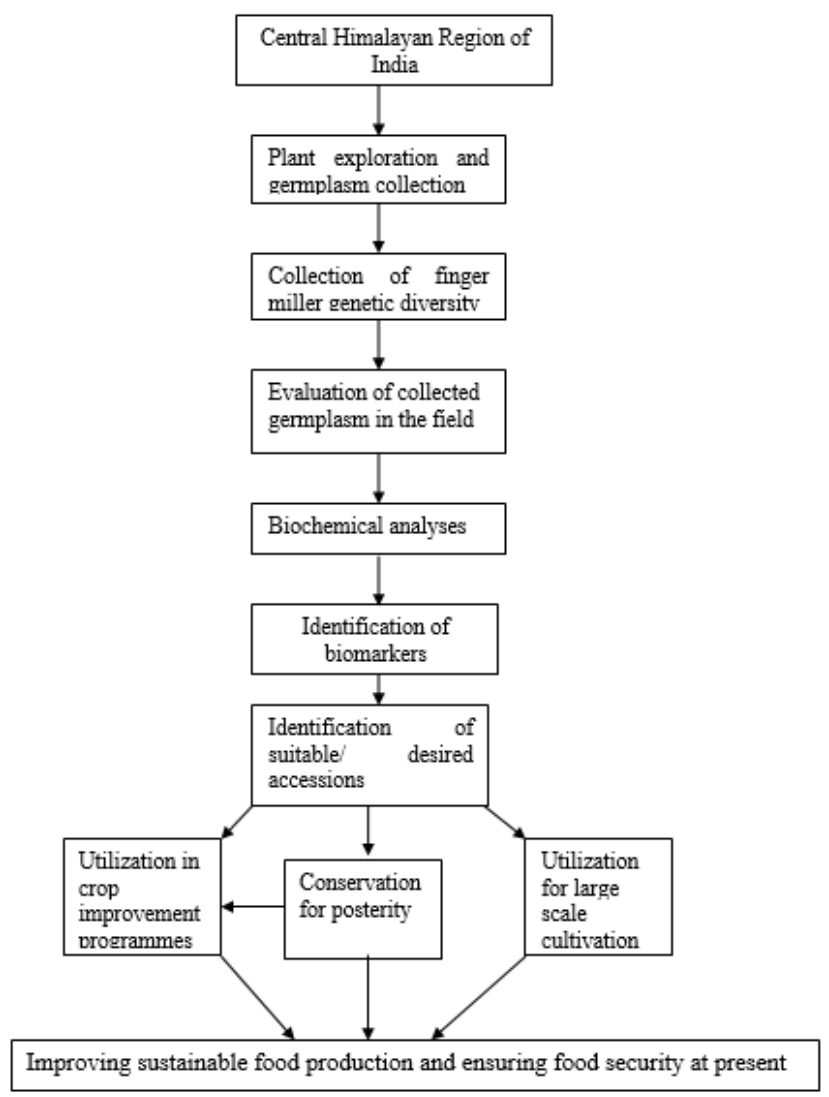

Figure 1

Graphical Abstract

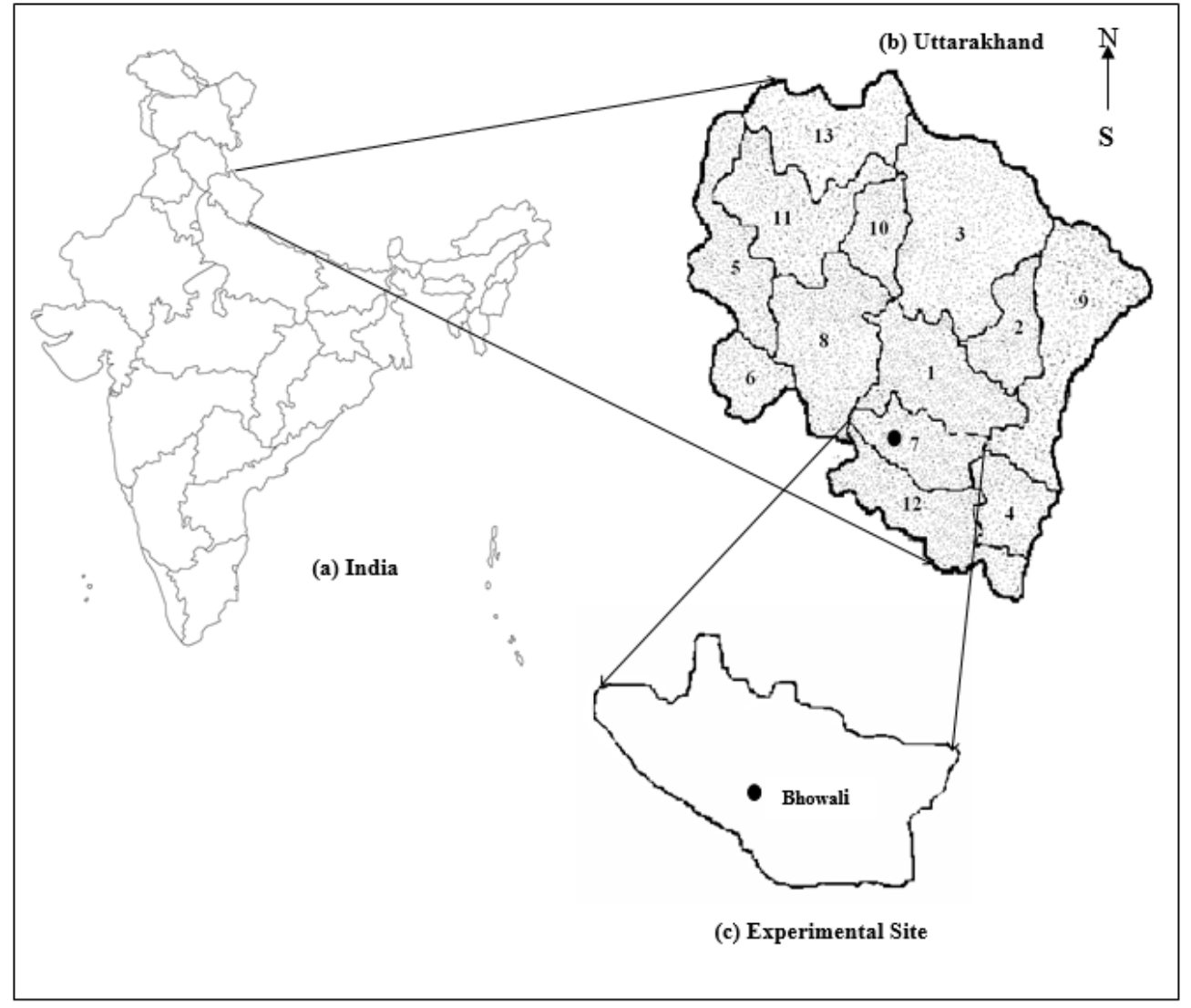

Figure 2 
(a) Map of India (left upper); (b) Central Himalayan Region i.e., Uttarakhand (distribution map) (right upper); (c) ICAR - NBPGR, Regional Station Bhowali i.e., Location of experimental site (right lower) with amplification.

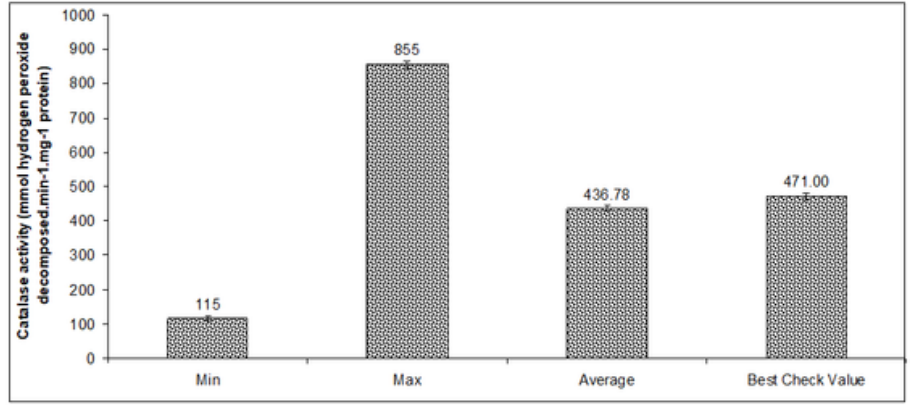

A

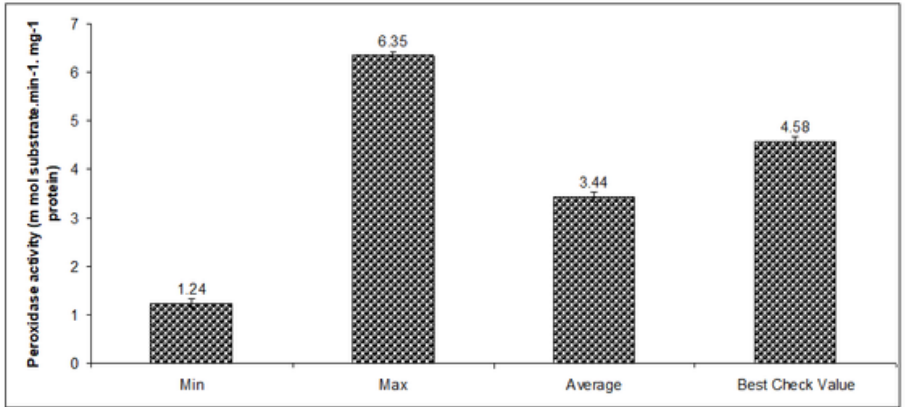

B

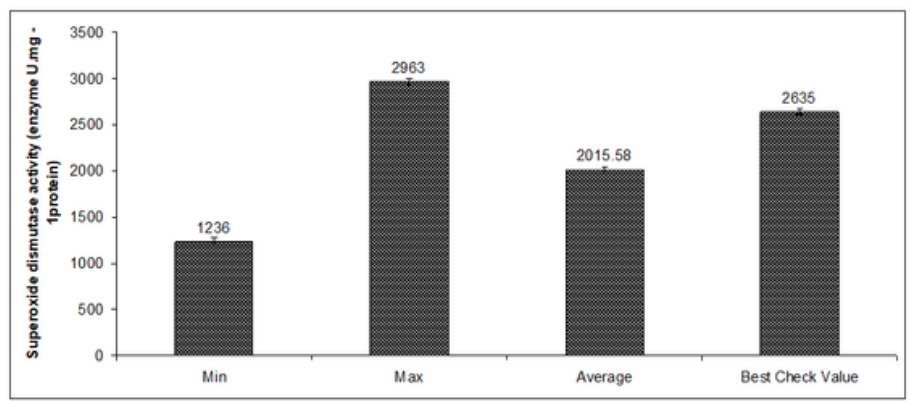

C

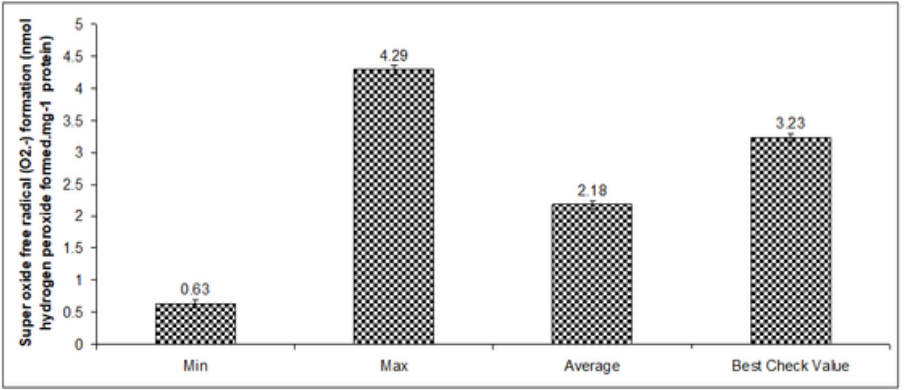

D

\section{Figure 3}

(a) Catalase activity (mmol hydrogen peroxide decomposed.min-1.mg -1protein) (b) Peroxidase activity ( $\mathrm{m}$ mol substrate.min-1. mg-1 protein) (c) Superoxide dismutase activity (enzyme U.mg -1 protein) (d) Super oxide free radical (02.-) formation (nmol hydrogen peroxide formed.mg-1 protein) 

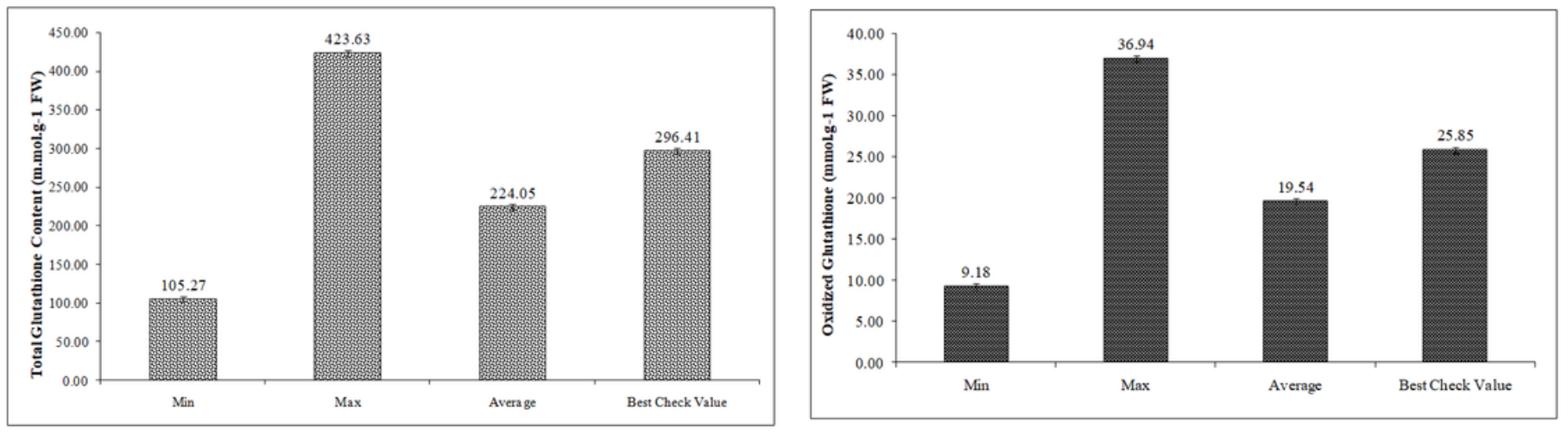

A

C
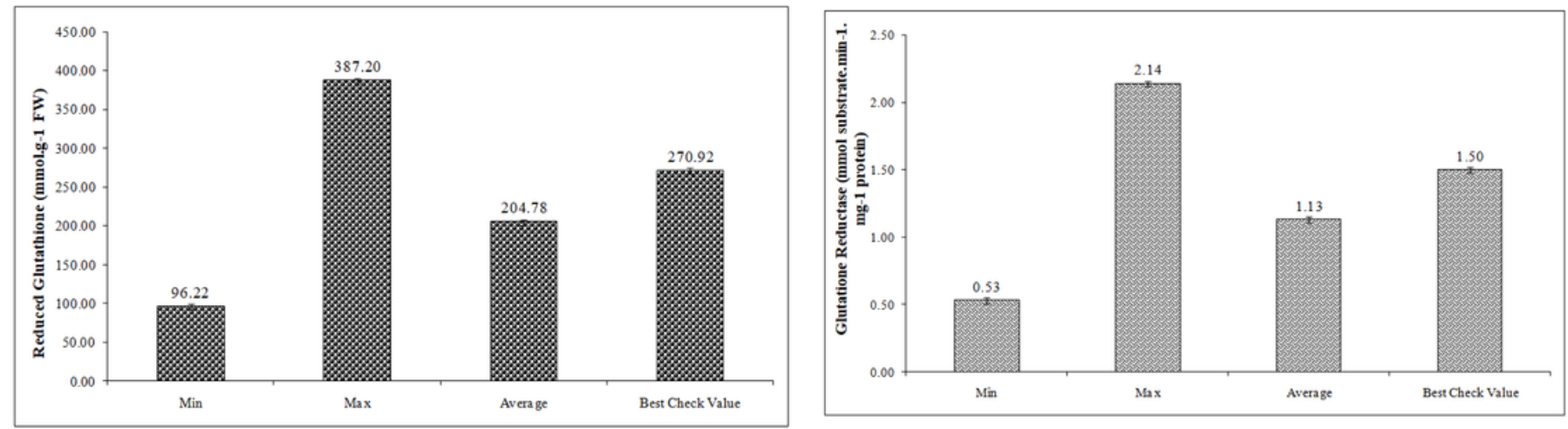

B

D

\section{Figure 4}

(a) Total Glutathione Content (mmol.g-1 FW) (b) Reduced Glutathione Content (mmol.g-1 FW) (c) Oxidized Glutathione Content (mmol.g-1 FW)

(d) Glutatione Reductase Activity (mmol substrate.min-1. mg-1 protein)
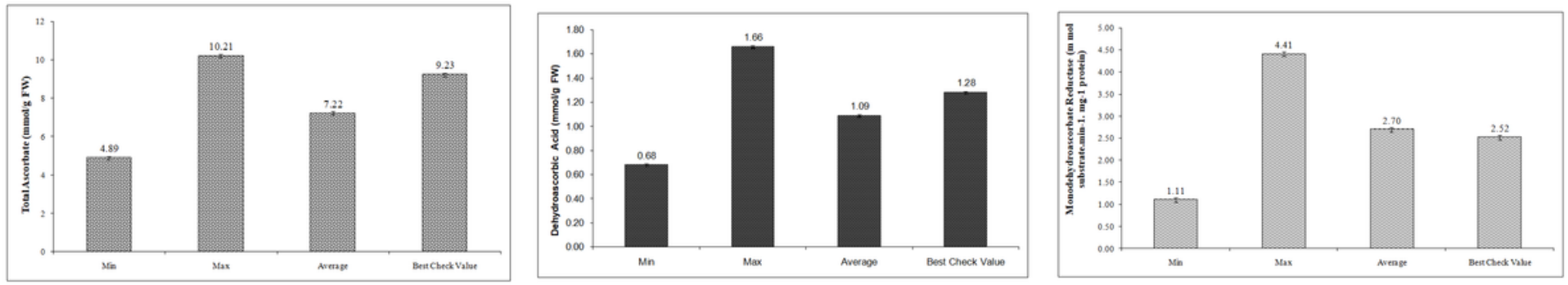

A

C

\section{$\mathrm{E}$}
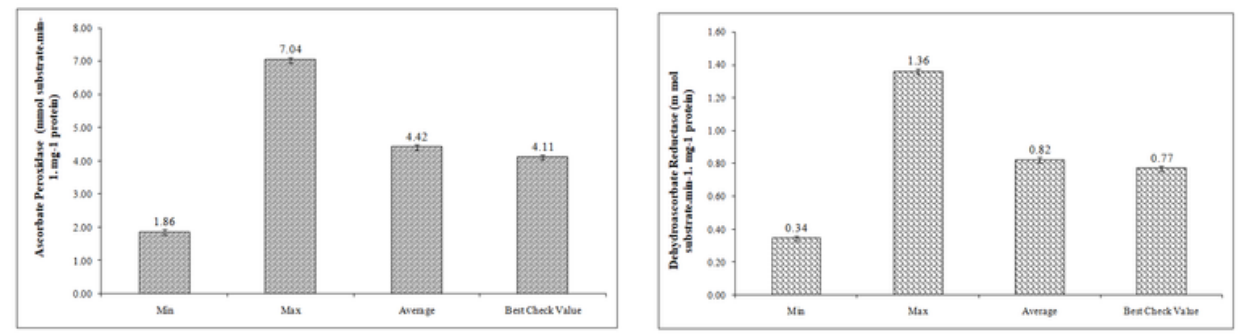

D

$\mathrm{F}$

Figure 5

(a) Total Ascorbate Content (mmol.g-1 FW) (b) Ascorbic Acid Content (mmol.g-1 FW) (c) Dehydroascorbic Acid Content (mmol.g-1 FW) (d) Ascorbate Peroxidase Activity (mmol substrate.min-1. mg-1 protein) (e) Monodehydroascorbate Reductase Activity (m mol substrate.min-1. mg-1 protein) (f) Dehydroascorbate Reductase Activity (m mol substrate.min-1. mg-1 protein) 


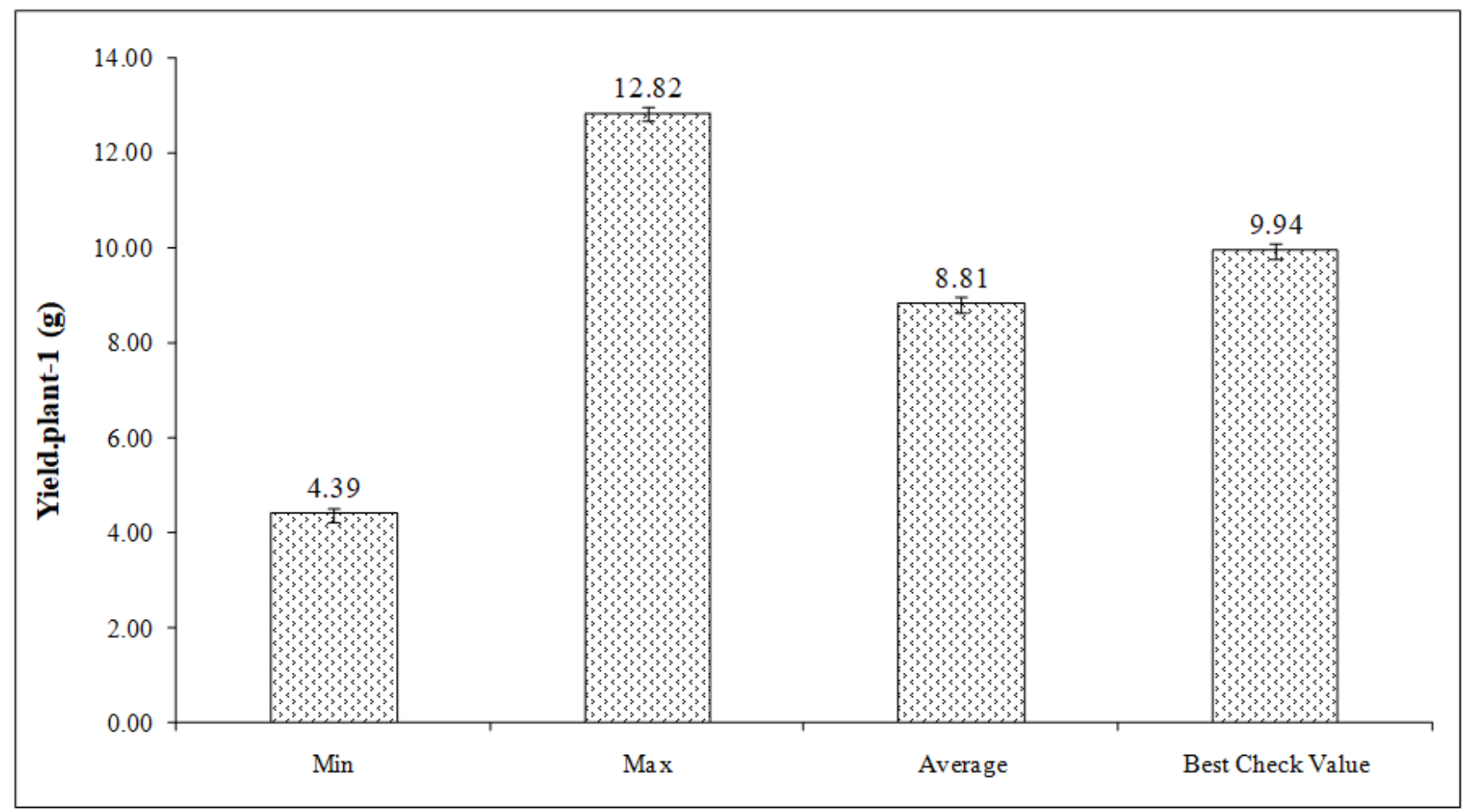

Figure 6

Yield.plant-1 (g)

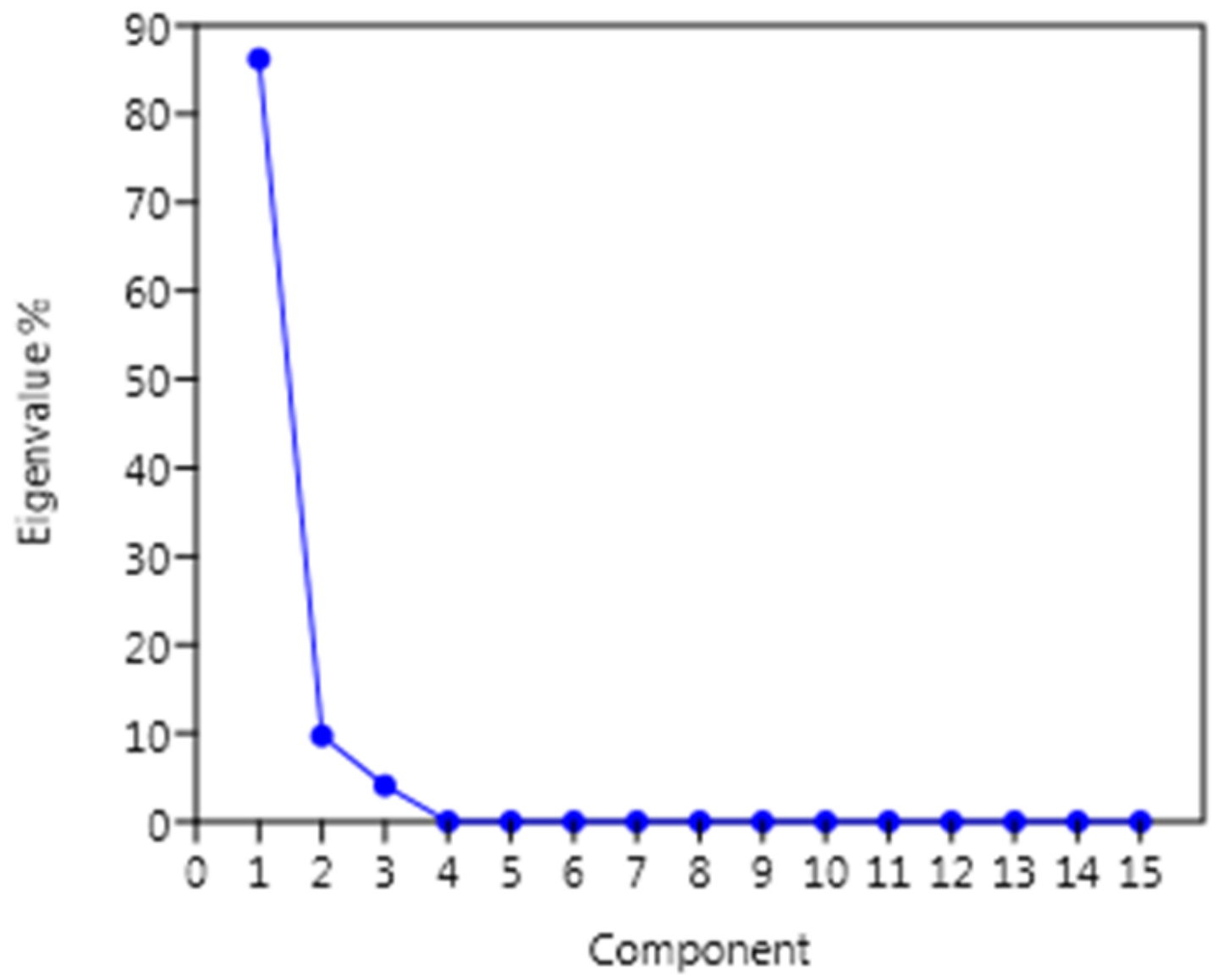

Figure 7

Page 15/16 
Scree plot of principal components.

\section{Supplementary Files}

This is a list of supplementary files associated with this preprint. Click to download.

- SupplementaryData.xls 